ORIGINAL ARTICLE

\title{
Zafirlukast for severe recurrent vulvovaginal candidiasis: an open label pilot study
}

\author{
D J White, A Vanthuyne, P M Wood, J G Ayres
}

Sex Transm Infect 2004;80:219-222. doi: 10.1136/sti.2002.003491

See end of article for authors' affiliations .....................

Correspondence to: Dr D J White, Hawthorn House, Department of Sexual Medicine, Birmingham Heartlands Hospital, Hospital, Bordesley Green East, Birmingham B9 5SS, UK; David.white@heartsol. wmids.nhs.uk

Accepted for publication 22 September 2003

\begin{abstract}
Background: Recurrent vulvovaginal candidiasis (VVC) has been linked to allergic disease, particularly allergic rhinitis.

Objective: A pilot study to assess the possible use of the leukotriene receptor antagonist zafirlukast as a treatment for recurrent VVC.

Methods: 20 women with six or more symptomatic attacks of VVC in the past year lat least four proved microbiologically). Clinical atopy determined by the International Study for Asthma and Allergies in Childhood (ISAAC) questionnaire assessed blindly. Monitoring by daily symptom diary and self taken vaginal swabs. Treatment with zafirlukast $20 \mathrm{mg}$ twice daily for 24 weeks or until three microbiologically confirmed episodes of VVC. Response assessed by daily symptom diary and self taken vaginal swabs. Subjective response scales for improvement, side effects, and change in other allergic disease completed when stopping treatment. Semistructured telephone interview 1 year after stopping medication.

Results: 14 patients (70\%) reported a subjective response on the improvement response scale. Six (30\%) showed a complete response with no further symptomatic attacks of VVC or negative swabs when symptomatic. Seven (37\%) remained symptom free 18 months after entering the study-that is, 12 months after stopping therapy. 11 (58\%) remained symptom free for at least 3 months after stopping therapy. This does not include one patient who remained symptom free but continued on zafirlukast because of an improvement in her asthma. There was no clear relation between response and atopic status. Six of nine atopic subjective responders reported improvements in other allergic symptoms. Side effects were minimal; one seemed clearly attributable to the drug.

Conclusion: Zafirlukast offers a potential new treatment for recurrent VVC that requires confirmation in controlled studies.
\end{abstract}

$\mathrm{V}$ ulvovaginal candidiasis (VVC) caused by Candida albicans is a common condition. In a recent random telephone dialling health survey in the United States $6.5 \%$ of adult women reported an episode of VVC in the past 2 months. ${ }^{1}$ The same survey had $8.0 \%$ reporting a history of recurrent disease, defined as more than four attacks per year. This was estimated to cost $\$ 58.4$ million per year in medical care and \$19.8 million per year in medication costs for the United States. For such a common condition treatment options are limited. While treatment with azole antifungals is very effective for episodic VVC, standard short courses do not prevent relapse in recurrent $\mathrm{VVC}^{2}$ which needs to be differentiated from other conditions such as chronic infection with non-C albicans yeasts and vulval dermatitis. ${ }^{3}$ Currently the only treatment recommended for recurrent VVC in the UK national guidelines is suppression using oral or vaginal azole antifungals ${ }^{4}$ based on a number of open label, nonrandomised studies. Relapse commonly occurs when treatment is stopped.

The pathogenesis of recurrent VVC is poorly understood. Data from humans and animals suggest that, at least in some patients, an aberrant local vaginal immune response ${ }^{6}$ may be important in allowing persistent clonal colonisation of the vagina with $C$ albicans in amounts too small to be cultured (so called vaginal relapse). ${ }^{7-9}$ Recurrent symptoms occur when multiplication of these initially small amounts of $C$ albicans and cultures then become positive once more. ${ }^{8}{ }^{10}{ }^{11}$ A possible link of recurrent VVC to allergy was first suggested by Kudelko in $1971^{12}$ and more recently Moraes has suggested this is specifically to allergic rhinitis. ${ }^{13}$ This has led to three open label studies which have suggested that desensitisation with candidal antigens may be effective in recurrent VVC..$^{14-17}$
Other allergy related therapeutic approaches have not been explored. Leukotrienes are mediators of inflammation produced by the metabolism of arachidonic acid. ${ }^{18}$ They have been shown to be of importance in the epithelial inflammation associated with asthma ${ }^{19}$ and allergic rhinitis. Leukotriene receptor antagonists have been shown to be effective forms of treatment in some patients with these conditions. ${ }^{20-23}$ We report an open label study of zafirlukast (Accolate, Astra Zeneca Pharma), a leukotriene receptor antagonist, in recurrent VVC.

\section{METHODS}

\section{Study design}

This was an open label pilot study.

\section{Inclusion/exclusion criteria}

Patients were eligible for the study if they had experienced six or more symptomatic attacks of VVC in the past year, of which four or more were microbiologically proved. They also described a clear, even if short lived, response to short course azole antifungal treatment-that is, 1 day courses of oral azole antifungals or 1-7 day courses of azole pessaries. Microbiological proof required vaginal swabs showing either a moderate or heavy growth of Candida species or hyphae and spores on microscopy. At least one positive swab within a month of study entry had been confirmed as $C$ albicans. Exclusion criteria included a history of diabetes, impaired glucose tolerance, any other chronic disease except atopic asthma, eczema or rhinitis, treatment with oral steroids, pregnancy or breast feeding in the past year, post-menopausal state or taking any non-contraceptive hormone therapy. 


\section{Treatment and follow up}

Treatment was with zafirlukast $20 \mathrm{mg}$ twice daily to study exit. Patients were reviewed 4 weeks after entry for liver function tests and then 24 weeks after entry when medication was stopped. Patients could exit the study if they had three microbiologically proved episodes of VVC.

\section{Investigations at entry}

Entry liver function tests, random blood sugar, and full blood counts were all normal. Skin prick tests were performed at entry with a battery of aeroantigens including Der Pl (house dust mite), six grass mix, cat dander, three tree mix, Alternaria alternata, Aspergillus fumigatus, and positive and negative controls (ALK-Abello, High Wycombe, UK). A positive test was indicated by a weal $3 \mathrm{~mm}$ in diameter greater than the negative control. The International Study for Asthma and Allergies in Childhood (ISAAC) questionnaire was completed to define the presence of allergic rhinitis, allergic conjunctivitis, asthma, and eczema. The ISAAC questionnaire is a validated epidemiological tool for allergic diseases. Although originally designed for use in children and adolescents it has been used in older populations. ${ }^{24}$ The questionnaires were assessed blindly by PMW and JGA with consensus over discrepant results. The questionnaire and skin prick testing were part of a larger study looking at the association between recurrent VVC and allergic rhinitis. ${ }^{25}$ The data from this will be presented in a separate paper which will include the results of skin testing with a number of candidal antigens.

\section{Follow up investigations}

Liver function tests were taken 4 weeks after starting zafirlukast. Symptom diaries were kept recording any symptoms of vulval discomfort/itching grading this as mild, moderate, or severe. During the treatment period patients were asked, if possible, to self take vaginal swabs if they had possible symptoms of VVC with moderate/severe symptoms of itching for at least 2 days. These were directly smeared onto a microscope slide, placed into Stuart's transport media, and brought into the department within 4 hours for Gram staining and direct plating onto Sabouraud's media. Patients were allowed to self medicate if they had an episode of moderate/severe itching preferably after swabs had been taken. Treatment was with itraconazole $200 \mathrm{mg}$ twice daily for 1 day, clotrimazole $500 \mathrm{mg}$, or econazole $150 \mathrm{mg}$ single dose pessary according to the patient's preference. This was not recorded specifically in the diary.

For the purposes of analysis a subjective episode of VVC was defined as a discrete period of moderate or severe discomfort/itching lasting at least 2 days, with at least 2 days of no symptoms before or after an adjoining episode. These were considered proved episodes when culture positive. A complete response was defined by either having no further symptomatic episodes of VVC or having negative swabs- that is, no growth, for any subjective episodes. A subjective response was defined by an "improvement" scale of 5 or more at study completion.

At exit or study completion patients were asked to complete a questionnaire. This consisted of scales with a $9 \mathrm{~cm}$ line marked between 1 and 10 at $1 \mathrm{~cm}$ intervals. Patients were asked to score between 1 (nil score) to 10 (maximal score) for "response to treatment," "would take it again if the same problem," and "side effects". A similar scale was also included for "change in symptoms of allergic disease" with 1 representing much worse, 5 no change, and 10 completely better.

One year after stopping therapy all patients who did not have a documented outcome were contacted by phone for a short semistructured interview to assess long term response.
This study was approved by the East Birmingham local research ethics committee.

\section{Statistics}

Statistical tests were applied using StatView for Windows Version 4.57 for linear regression and Epi-Info 2000 for Fisher's exact test.

\section{RESULTS}

\section{Patients}

Twenty women were entered into the study between February 2000 and August 2001. They were aged between 21 and 48 years old (mean age 33). Eighteen indicated their ethnic origin using the standard Department of Health categories as white, one as Afro-Caribbean, and one as "other ethnic group." They reported between eight and 24 (mean of 12) symptomatic attacks of VVC in the previous year. The history of recurrent VVC ranged between 9 months and 20 years (mean 4.5, median 8). One patient was symptomatic at entry. This responded to antifungals and was not included in the subsequent analysis.

The overall results are summarised in table 1.

\section{Dropouts}

One patient kept her symptom diary for only the first 12 weeks. In this time she recorded three episodes of symptomatic VVC but had taken only one swab, which was positive. She was included as a non-responder and the rate of VVC doubled for the purposes of analysis for to take account of the missing data.

One atopic subjective responder stopped zafirlukast after 21 weeks of treatment after bereavement. She returned after 7 months when she completed the study exit form but did not return her symptom diary. She did however state she had been completely symptom free apart from one culture proved attack of VVC. She is included as a subjective but non"complete" responder. She gave long term follow up information 1 year after stopping treatment.

\section{Atopy}

Of the 20 patients 12 were judged as having atopic disease from the ISAAC questionnaire (a similar proportion to that described by Moraes $^{13}$ and in the larger study that these patients were part of (White DJ, et al unpublished results)). All of these had allergic rhinitis, seven allergic conjunctivitis, four asthma, two eczema. All clinically atopic patients except one had a positive reaction to one or more of the skin prick test antigens.

\section{Response to therapy}

Two patients exited the study early (at 12 and 16 weeks) after three culture proved symptomatic episodes.

Six patients were complete responders, two of whom were clinically atopic. They had had recurrent VVC between 9 months to 16 years (mean 7.6, median 7). Two patients had had 10 and four had had 12 symptomatic attacks in the year before starting zafirlukast.

Fourteen patients were subjective responders with improvement scores of 5 or more. Nine were clinically atopic. They had had recurrent VVC between 0.75 and 20 years (mean 8, median 7.5). They had had between eight and 24 symptomatic attacks in the previous year.

There was no clear association between complete response (Fisher's exact test $\mathrm{p}=0.67$ ) or subjective response (Fisher's exact test $\mathrm{p}=1.0$ ) and atopic status.

Some patients lived a considerable distance away from the clinic and because of the need to bring swabs to the study centre in a timely manner not all subjective episodes had microbiological proof. A total of 56 subjective episodes of VVC 
Table 1 Results of therapy: mean values (median in parentheses)

\begin{tabular}{|c|c|c|c|c|c|c|c|c|c|c|c|c|c|}
\hline & No & $\begin{array}{l}\text { No } \\
\text { atopic }\end{array}$ & $\begin{array}{l}\text { No } \\
\text { combined } \\
\text { pill }\end{array}$ & $\begin{array}{l}\text { Duration } \\
\text { recurrent } \\
\text { VVC } \\
\text { (years) }\end{array}$ & $\begin{array}{l}\text { Episodes } \\
\text { subjective } \\
\text { VVC in } \\
\text { previous } \\
\text { year }\end{array}$ & $\begin{array}{l}\text { Episodes } \\
\text { subjective } \\
\text { VVC } \\
\text { during } \\
\text { treatment* }\end{array}$ & $\begin{array}{l}\text { Episodes } \\
\text { subjective } \\
\text { VVC during } \\
\text { treatment* } \\
\text { (minus -ve } \\
\text { swabs) }\end{array}$ & $\begin{array}{l}\text { No } \\
\text { swabs } \\
\text { taken* }\end{array}$ & $\begin{array}{l}\text { No } \\
\text { positive } \\
\text { swabs }^{*}\end{array}$ & $\begin{array}{l}\text { Improve- } \\
\text { ment } \\
\text { exit } \\
\text { score }\end{array}$ & $\begin{array}{l}\text { Take } \\
\text { again } \\
\text { exit } \\
\text { score }\end{array}$ & $\begin{array}{l}\text { Side } \\
\text { effects } \\
\text { exit } \\
\text { score }\end{array}$ & $\begin{array}{l}\text { No } \\
\text { symptom } \\
\text { free } 1 \text { year } \\
3 \text { months) } \\
\text { post- } \\
\text { treatment }\end{array}$ \\
\hline $\begin{array}{l}\text { "Complete" } \\
\text { responders }\end{array}$ & 6 & 2 & 1 & $7.6(7)$ & $11.4(12)$ & $0.8(0)$ & $0.8(0)$ & $1.6(2)$ & $0.2(0)$ & $10(10)$ & $10(10)$ & $1.5(1)$ & $4(6)$ \\
\hline $\begin{array}{l}\text { Non- } \\
\text { complete" } \\
\text { responders }\end{array}$ & 14 & 10 & 2 & $7.8(4.5)$ & $12.8(12)$ & $5.5(5)$ & $5.5 .1(5)$ & $2.6(2.5)$ & $2.0(2)$ & $4.7(6)$ & $5.5(5.4)$ & $1(1)$ & $3(5) \dagger$ \\
\hline $\begin{array}{l}\text { Subjective } \\
\text { responders }\end{array}$ & 14 & 9 & 2 & $8.1(7.5)$ & $12.4(10)$ & $2.6(2)$ & $2.6(2)$ & $1.8(2)$ & $1(0.93)$ & $8.4(8)$ & $9.1(10)$ & $1.5(1)$ & $7(11) \dagger$ \\
\hline $\begin{array}{l}\text { Subjective } \\
\text { non- } \\
\text { responders }\end{array}$ & 6 & 3 & 1 & $6.9(2.8)$ & $12.3(12)$ & $7.9(6)$ & $7.9(6)$ & $3.9(4)$ & $3.9(4)$ & 1.7 (1.5) & $1.3(1)$ & $1(1)$ & $0(0)$ \\
\hline
\end{tabular}

were recorded for which 44 self swabs were taken. Thirty of these proved positive for Candida. Although collected retrospectively at study exit, response on the improvement score, correlated significantly with prospectively collected symptomatic data-that is, the number of subjective episodes of symptomatic VVC (minus negative swabs) $(r=0.67$, $\mathrm{p}=0.0013$ by simple linear regression).

Six of nine atopic subjective responders reported an "improvement in other allergic disease" score of 7 or more for one of their allergic conditions. The one asthmatic patient chose to stay on zafirlukast because of an improvement in her asthma.

\section{Adverse events}

Adverse events were reported in four patients. One reported intermenstrual bleeding on the progesterone pill and gave a side effects score of 8 because of this. The other three patients reported a side effects score of 1 . Of these one reported nasal irritation at the time of symptomatic attacks of VVC which settled by 4 months. One developed eczema which settled after 2 months. One complete responder reported worsening seborrhoeic dermatitis, which did not settle and required referral to a dermatologist. All liver function tests were within the normal ranges at entry and 4 weeks after starting zafirlukast.

\section{Post-treatment follow up}

Long term follow up data up are available up to 1 year after stopping zafirlukast for all 20 participants. Of the responders one remained on zafirlukast because of an improvement in her asthma and remained symptom free. Seven remained symptom free 1 year after stopping zafirlukast. Three were symptom free when stopping zafirlukast but relapsed after 3, 4 , and 7 months and then re-responded on restarting zafirlukast. One relapsed after 7 months when pregnant. Two who had had a subjective response worsened on stopping zafirlukast and then opted to go onto suppressive antifungal treatment.

\section{DISCUSSION}

These results show a complete short term symptomatic response to treatment with zafirlukast in six $(30 \%)$ of 20 women with mostly long standing and very frequently recurrent VVC. A subjective response was seen in $14(70 \%)$ of 20 patients. Eleven of 19 (58\%) remained symptom free for at least 3 months after stopping zafirlukast.

The findings of this pilot study show that zafirlukast may offer an alternative treatment to suppressive antifungals for women affected by recurrent VVC. This will need to be confirmed in a randomised and preferably placebo controlled clinical trial especially in view of the subjective nature of the data presented. Such studies should compare not only the short term response but also the long term remission rate since this was comparable in responders to that seen in similar studies of suppressive antifungals. ${ }^{5}$ Currently zafirlukast can not be recommended as first line treatment. It may be worthwhile considering if there are no reasonable alternatives or when zafirlukast is indicated for another licensed indication.

The main end point for this study was based on subjective symptoms of vulval soreness/itching. VVC is a syndrome rather than the presence or absence of an infection ${ }^{26}$ and such subjectivity is a problem in studying other possibly related conditions-for example, allergic rhinitis. ${ }^{13}$ Our experience in this study highlights the importance but also the difficulty of obtaining microbiological confirmation of subjective episodes of VVC when participants need to deliver swabs within a short time to a central site or laboratory.

There were no side effects clearly attributable to the drug apart from in one patient who developed worsening of their seborrhoeic dermatitis, not previously recorded as a side effect of treatment with oral leukotriene receptor antagonists. Oral antifungals, like zafirlukast, may rarely be associated with hepatitis. Vaginal antifungals are not described as having systemic side effects and are safe in pregnancy but many women find them messy and inconvenient and they may also cause local irritation. Zafirlukast offers the additional possibility of improvement in other allergic disease and six of the nine atopic responders reported such improvements. Since this was not the main aim of the study these were based only on symptom scales and did not include objective measurements such as peak flow measurements. This is however consistent with published studies of zafirlukast and other leukotriene receptor antagonists in atopic disease. ${ }^{20-22}$

This study arose from the association between allergic rhinitis and recurrent VVC reported by Moraes. ${ }^{27}$ The finding that atopic status did not clearly predict response to zafirlukast was therefore unexpected. It has been suggested by Fidel that recurrent VVC may be due to an abnormality of vaginal Thl cytokine expression expressed at the level of vaginal epithelial cells. ${ }^{6}$ Our findings raise the possibility that this may be linked to inflammation caused by vaginal leukotriene production. A predisposition to such an inflammatory response may be only variably expressed in some individuals as allergic rhinitis. Although 35\% of patients reported a complete response with no further attacks the response rate varied overall. In asthma and allergic rhinitis, 
the leukotriene pathway represents just one of a number of pro-inflammatory pathways and the lack of response in some patients in this study may reflect the involvement of other such pathways. Alternatively, the variable response may represent a dose-response effect. Dose-response effects have been seen for zafirlukast in asthma ${ }^{28}$ but less obviously so for montelukast, where a plateau of effect is seen at $10 \mathrm{mg}$ per day. ${ }^{29}$ If local inflammation is a key process in recurrent VVC then the remission that sometimes occurs after suppressive antifungal therapy may possibly be the result of a reduction in such inflammation. Combination therapy with suppressive antifungals and zafirlukast might therefore conceivably have an adjunctive effect. This possibility needs exploring in further studies.

\section{CONCLUSION}

In this open label pilot study zafirlukast taken for 6 months appears to offer a potential new alternative treatment to suppressive antifungals for recurrent VVC with a 30\% complete response while the patient is on therapy and a $37 \%$ complete response 1 year after stopping therapy in an open pilot study. This needs confirmation in double blind placebo controlled studies, which ideally should include comparison with, and in addition to, suppressive antifungal therapy.

\section{Authors' affiliations}

D J White, A Vanthuyne, Hawthorn House, Department of Sexual Medicine, Birmingham Heartlands Hospital, Hospital, Bordesley Green East, Birmingham B9 5SS, UK

J G Ayres, Department of Respiratory Medicine, Birmingham Heartlands Hospital, Bordesley Green East, Birmingham B9 5SS, UK

P M Wood, Department of Clinical Biochemistry and Immunology, Leeds General Infirmary, Great George Street, Leeds LSI 3EX, UK

\section{REFERENCES}

1 Foxman B, Barlow R, D'Arcy $H$, et al. Candida vaginitis: self-reported incidence and associated costs. Sex Transm Dis 2000;27:230-5.

2 Sobel JD, Kapernick PS, Zervos M, et al. Treatment of complicated Candida vaginitis: comparison of single and sequential doses of fluconazole. Am J Obstet Gynecol 2001;185:363-9.

3 Geiger AM, Foxman B, Sobel JD. Chronic vulvovaginal candidiasis: characteristics of women with Candida albicans, C glabrata and no candida. Genitourin Med 1995:71:304-7.

4 Clinical Effectiveness Group. National Guideline on the Managment of Vulvovaginal Candidiasis. Association for Genitourinary Medicine and the Medical Society for the Study of Venereal Diseases. 2002.

5 Marazzo J. Vulvovaginal candidiasis. Clinical Evidence 2002;7:1784-96.

6 Fidel PL Jr. Vaginal candidiasis: review and role of local mucosal immunity. [Review] [62 refs]. AIDS Patient Care Stds 1998;12:359-66.

7 El-Din SS, Reynolds MT, Ashbee HR, et al. An investigation into the pathogenesis of vulvo-vaginal candidosis. Sex Transm Infect 2001;77:179-83.
8 Lockhart SR, Reed BD, Pierson CL, et al. Most frequent scenario for recurrent Candida vaginitis is strain maintenance with "substrain shuffling": demonstration by sequential DNA fingerprinting with probes $\mathrm{Ca} 3, \mathrm{Cl}$, and CARE2. J Clin Microbiol 1996;34:767-77.

9 Vazquez JA, Sobel JD, Demitriou R, et al. Karyotyping of Candida albicans isolates obtained longitudinally in women with recurrent vulvovaginal candidiasis. J Infect Dis 1994;170:1566-9.

10 Giraldo P, von Nowaskonski A, Gomes FA, et al. Vaginal colonization by Candida in asymptomatic women with and without a history of recurrent vulvovaginal candidiasis. Obstet Gynecol 2000;95:413-16.

11 Nelson AL. The impact of contraceptive methods on the onset of symptomatic vulvovaginal candidiasis within the menstrual cycle. Am J Obstet Gynecol 1997; 176:1376-80.

12 Kudelko NM. Allergy in chronic monilial vaginitis. Ann Allergy $1971 ; 29: 266-7$.

13 Moraes PS. Recurrent vaginal candidiasis and allergic rhinitis: a common association. Ann Allergy Asthma Immunol 1998;81:165-9.

14 Rosedale N, Browne K. Hyposensitisation in the management of recurring vaginal candidiasis. Ann Allergy 1979;43:250-3.

15 Rigg D, Miller MM, Metzger WJ. Recurrent allergic vulvovaginitis: treatment with Candida albicans allergen immunotherapy. Am J Obstet Gynecol 1990;162:332-6.

16 Moraes PS, de Lima GS, Taketomi EA. Candida albicans allergen immunotherapy in recurrent vaginal candidiasis. J Invest Allergol Clin Immunol 2000;10:305-9.

17 Birinci A, Sanic A, Durupinar B. Determination of minumum inhibitory concentrations of Candida species isolated from vaginal swab specimens by using broth macrodilution and E-test. J Chemother 2001;13:43-6.

18 Samuelsson B, Borgeat $P$, Hammarstrom S, et al. Introduction of a nomenclature: leukotrienes. Prostaglandins 1979;17:785-7.

19 Griffin M, Weiss JW, Leitch AG, et al. Effects of leukotriene D on the airways in asthma. N Engl J Med 1983;308:436-9.

20 Lipworth BJ. Emerging role of antileukotriene therapy in allergic rhinitis. [Review] [49 refs]. Clin Exp Allergy 2001;31:1813-21.

21 Suissa S, Dennis R, Ernst $P$, et al. Effectiveness of the leukotriene receptor antagonist zafirlukast for mild-to-moderate asthma. A randomized, doubleblind, placebo-controlled trial. [See comments.]. Ann Intern Med 1997; 126:177-83

22 Reiss TF, Chervinsky P, Dockhorn RJ, et al. Montelukast, a once-daily leukotriene receptor antagonist, in the treatment of chronic asthma: a multicenter, randomized, double-blind trial. Montelukast Clinical Research Study Group. Arch Intern Med 1998;158:1213-20.

23 Smith PD, Lamerson CL, Banks SM, et al. Granulocyte-macrophage colonystimulating factor augments human monocyte fungicidal activity for Candida albicans. J Infect Dis 1990;161:999-1005.

24 Vichyanond P, Sunthornchart S, Singhirannusorn V, et al. Prevalence of asthma, allergic rhinitis and eczema among university students in Bangkok. Resp Med 2002;96:34-8.

25 White DJ, Vanthuyne A, Wood PM, et al. Recurrent vulvovaginal candidiasis an atopic disease? A case control study. Annual Spring Meeting. 2002. Oslo-Norway, Medical Society for the Study of Venereal Diseases.

26 Sobel JD, Faro S, Force RW, et al. Vulvovaginal candidiasis: epidemiologic, diagnostic, and therapeutic considerations. [see comments.]. [Review] [29 refs]. Am J Obstet Gynecol 1998;178:203-11.

27 Moraes PS. Recurrent vaginal candidiasis and allergic rhinitis: a common association. Ann Allergy Asthma Immunol 1998:81:165-9.

28 Suissa S, Dennis R, Ernst $P$, et al. Effectiveness of the leukotriene receptor antagonist zafirlukast for mild-to-moderate asthma. A randomized, doubleblind, placebo-controlled trial. [see comments.]. Ann Intern Mede 1997; 126:177-83.

29 Spector SL, Smith U, Glass M. Effects of 6 weeks of therapy with oral doses of ICl 204,219, a leukotriene D4 receptor antagonist, in subjects with bronchial asthma. ACCOLATE Asthma Trialists Group. Am J Resp Crit Care Med $1994 ; 150: 618-23$ 